\title{
Potassium and insulin affect the contractility of abomasal smooth muscle
}

\author{
G. Türck and S. Leonhard-Marek ${ }^{1}$ \\ Department of Physiology, University of Veterinary Medicine, Bischofsholer Damm 15, 30173 Hannover, Germany
}

\begin{abstract}
Abomasal displacement is a frequent and important disease of high yielding dairy cows. Although several factors are related to its occurrence, the pathogenesis of the condition is still inadequately understood, particularly in regard to $\mathrm{K}^{+}$and insulin homeostasis. For this reason the aim was to investigate the effects of $\mathrm{K}^{+}$and insulin concentrations on in vitro motility of abomasal smooth muscle. The second aim was to determine whether the in vivo change in $\mathrm{K}^{+}$and insulin levels might be sufficient to induce reduced abomasal motility. Muscle strips were isolated from the abomasum of slaughtered cows and incubated in buffer solution under isometric conditions. Results show that a decrease in extracellular $\mathrm{K}^{+}$(between 5 and $1 \mathrm{mmol} / \mathrm{L}$ ) or an increase in extracellular insulin concentrations (to 21 $\mathrm{mU} / \mathrm{L}$ or higher) were able to affect the contraction activity of abomasal muscles. Contraction activity given as median (25th, 75th percentiles) changed from 28.1 $\mathrm{mN} / \mathrm{min}(2.5,49.9)$ at $5 \mathrm{mmol} / \mathrm{L}$ of $\mathrm{K}^{+}$to $9.4 \mathrm{mN} /$ $\min (0.6,35.7)$ at $1 \mathrm{mmol} / \mathrm{L}$ of $\mathrm{K}^{+}$, and from $34.5 \mathrm{mN} /$ $\min (10.8,112.4)$ at $0 \mathrm{mU} / \mathrm{L}$ of insulin to $12.0 \mathrm{mN} / \mathrm{min}$ $(7.6,49.8)$ at $120 \mathrm{mU} / \mathrm{L}$ of insulin. Because the effect of insulin could be abolished by barium, glybenclamide, or ouabain, the underlying mechanisms of the insulin action could be an increased $\mathrm{K}^{+}$conductance or an increased $\mathrm{Na} / \mathrm{K}$-ATPase activity or both. Low $\mathrm{K}^{+}$or high insulin concentrations both reduced the activity of the circular muscle of the abomasal corpus (i.e., of the part that is responsible for the propulsion of abomasal chymus) and might play an important role in the pathogenesis of abomasal displacement.
\end{abstract}

Key words: abomasal displacement, potassium, insulin, dairy cow

\section{INTRODUCTION}

Abomasal displacement (DA) is one of the most frequent and important diseases of high yielding dairy cows and most frequently affects animals from a few

Received December 3, 2009.

Accepted April 6, 2010.

${ }^{1}$ Corresponding author: sabine.leonhard-marek@tiho-hannover.de days before to 2 mo after parturition. The incidence of DA during lactation ranged between 1 and $7 \%$, but increased to $20 \%$ and higher in problem herds (Shaver, 1997; Doll et al., 2009). Although many factors were implicated in the occurrence of DA, the pathogenesis of the disease is still inadequately understood. Hypotony or atony of abomasal muscles was postulated as a prerequisite for the occurrence of DA (Dirksen, 1961), and prolonged phases of impairment of corpus activity could be shown by abomasal electromyography in cows (Kuiper and Breukink, 1988). Disturbed motility could prevent the passage of chymus and fermentation gases from the abomasum, which might in turn lead to gas accumulation and displacement of the organ. Hypokalemia and insulin imbalances are 2 possible causes of this observed hypotony.

Reduced feed intake generally precedes the development of DA (Shaver, 1997; Van Winden et al., 2003) and can cause a reduction in plasma $\mathrm{K}^{+}$(Clabough and Swanson, 1989). Cows with DA have lower values of serum $\mathrm{K}^{+}$(Delgado-Lecaroz et al., 2000; Zadnik, 2003; El-Attar et al., 2007), and within a group of afflicted cows, the $\mathrm{K}^{+}$levels were lower in those cows that did not recover or regain productivity (Rohn et al., 2004). Thus, low $\mathrm{K}^{+}$appears as a factor that plays a role in the pathogenesis of DA. Potassium affects the physiology of muscle cells. In humans, hypokalemia induced changes in the electroenterogram of the small intestine (Chen et al., 2005). A reduction in extracellular $\mathrm{K}^{+}$concentration enhances the gradient for $\mathrm{K}^{+}$diffusion out of the cells and is usually followed by a hyperpolarization of cell membranes. A prerequisite for the contraction of smooth muscle cells is the depolarization of the cell membrane up to a certain threshold potential, allowing for the opening of $\mathrm{Ca}^{2+}$ channels and for $\mathrm{Ca}^{2+}$ influx that is necessary for contraction.

Insulin in serum is generally reduced around parturition to ensure a sufficient flow of nutrients to the mammary glands (Giesecke, 1986), and cows that develop DA can have very low insulin before parturition (Van Winden et al., 2003), which might be explained by the lower DMI attributable to approaching parturition (Trenkle, 1970). On the other hand, an intense feeding regimen can induce significant increases in plasma insulin between 8 and 1 wk before parturition (Holtenius 
et al., 2003). Increased insulin was observed in cases with DA (Van Meirhaeghe et al., 1988b; Pravettoni et al., 2004; Sen et al., 2006) and was implicated as a factor in the pathogenesis of DA (Van Meirhaeghe et al., 1988b; Geishauser, 1995). Van Meirhaeghe et al. (1988a) observed decreases in abomasal emptying after an intravenous glucose infusion, followed by an increased secretion of endogenous insulin. The same observation was made after a bolus injection of exogenous insulin, which was followed by a decrease in plasma glucose. An experimental infusion with high doses of insulin reduced the abomasal efflux of cows under normoglycemic conditions (Holtenius et al., 2000), perhaps indicating a glucose-independent effect of insulin. Furthermore, cows that have undergone surgical correction for DA by omentopexy had a prolonged period of abnormal abomasal motility when plasma insulin concentrations persisted on a higher level (Pravettoni et al., 2004).

In humans and monogastric animals, higher secretion rates of insulin after a meal largely prevent food-induced increases, not only in plasma glucose but also in plasma $\mathrm{K}^{+}$concentrations, because both are taken up by skeletal muscle cells under the influence of insulin. Cellular $\mathrm{K}^{+}$uptake into skeletal muscle cells was stimulated via an insulin-dependent increase in $\mathrm{Na} / \mathrm{K}$ pump activity (Clausen, 2003). This was followed by an increase in pump current and a hyperpolarization of the cell membranes. Insulin was able to hyperpolarize the membrane of smooth muscle cells in capillaries, arteria, and vessel cultures, which was attributed to an insulin-dependent increase in $\mathrm{K}^{+}$conductance in these tissues (Berweck et al., 1993; Standen and Quayle, 1998; Yasui et al., 2008). High insulin might be followed by lower influx of $\mathrm{Ca}^{2+}$ and by reduced muscle contractility.

Given the disturbances in $\mathrm{K}^{+}$and insulin balances observed with DA and the interactions between $\mathrm{K}^{+}$, insulin, and the membrane potentials of muscle cells, the aim was to investigate the effects of $\mathrm{K}^{+}$and insulin on the motility of abomasal smooth muscles in vitro. The magnitude of the changes in $\mathrm{K}^{+}$and insulin levels that can be observed in vivo were assessed to determine whether they might be sufficient to induce a reduced motility of abomasal muscles, which could be a first step in the pathogenesis of DA.

\section{MATERIALS AND METHODS}

\section{Animals and Tissues}

Tissue samples of the abomasal wall were taken from 74 nonpregnant, healthy cows that had been slaughtered in a local abattoir. Within 30 min after slaughtering, samples were taken from the abomasal corpus and from the pyloric region and immediately rinsed with and in- cubated in buffer solution at $37^{\circ} \mathrm{C}$. Tissues were pinned flat into Petri dishes that had been coated with Sylgard (Dow Corning GmbH, Wiesbaden, Germany), a silicone elastomer. Mucosa and submucosa were dissected with forceps and scissors from the underlying muscle layers, and muscle strips $(0.5 \times 1.0 \mathrm{~cm})$ were cut out in the direction of the circular muscle layers.

\section{Incubation}

Muscle strips were fixed with commercially available inelastic yarn in the incubation chambers and to isometric force transducers (HBM, Berlin, Germany). Incubation chambers had a volume of $10 \mathrm{~mL}$, were kept at $37^{\circ} \mathrm{C}$ with the aid of a water jacket, and were gassed with carbogen $\left(95 \% \mathrm{O}_{2}\right.$ and $\left.5 \% \mathrm{CO}_{2}\right)$. Muscle strips were prestretched with a force of $20 \mathrm{mN}$ and allowed to equilibrate for $90 \mathrm{~min}$ before the first measurement was started.

\section{Motility Measurements}

The force transducers were connected to AD converters and a computer-controlled analysis system, which recorded muscle activity at a rate of $20 \mathrm{~Hz}$ (Spider 8 chart recorder, Catman Easy software version 1.01, HBM, Berlin, Germany). Muscle activity was determined over a period of 2 min before adding a substance and after the onset of an effect. Within these time frames the mean contraction amplitudes $(\mathrm{mN})$ and the mean contraction frequencies $(1 / \mathrm{min})$ were measured, whereas the contraction activity $(\mathrm{mN} / \mathrm{min})$ was calculated as the product of both (King and Gerring, 1988).

\section{Solutions and Drugs}

The standard buffer solution contained $(\mathrm{mmol} / \mathrm{L})$ $\mathrm{NaCl} 117.0, \mathrm{KCl} 4.7, \mathrm{MgCl}_{2} 1.2, \mathrm{NaH}_{2} \mathrm{PO}_{4} 1.2, \mathrm{CaCl}_{2}$ 2.5, $\mathrm{NaHCO}_{3} 25.0$, and glucose 11.0 and had a $\mathrm{pH}$ of 7.4 when gassed with carbogen $\left(95 \% \mathrm{O}_{2}\right.$ and $\left.5 \% \mathrm{CO}_{2}\right)$. To test for effects of $\mathrm{K}^{+}$, the concentration of $\mathrm{KCl}$ in the bathing solution was reduced to $1 \mathrm{mmol} / \mathrm{L}$. Aliquots of a $1 \mathrm{M} \mathrm{KCl}$ solution were added to increase the final concentration in the incubation chambers from 1 to 3 , $4,5,6,7$, and $10 \mathrm{mmol} / \mathrm{L}$ of $\mathrm{K}^{+}$. This range included values above and below the normal range of 4 to 5 $\mathrm{mmol} / \mathrm{L}$. One and $10 \mathrm{mmol} / \mathrm{L}$ were included to evaluate a 10-fold change in concentration. Equimolar additions of a $1 \mathrm{M} \mathrm{NaCl}$ solution to adjacent tissues served as control. To test for the effects of insulin, bovine insulin (Sigma-Aldrich, St. Louis, MO) was added from a stock solution to raise the concentration from 0 to $7,21,40$, 80 , and $120 \mathrm{mU} / \mathrm{L}$ in the incubation chambers. Addi- 
tion of equal volumes of the solvent (distilled water) to neighbor tissues served as control.

\section{Experimental Design}

In both $\mathrm{K}^{+}$and insulin dose response curves, the next concentration step was not applied before a steady state had been reached, but at the latest after $30 \mathrm{~min}$. Because the consecutive increases in insulin concentration did not induce any change in the contractility of muscles from the pyloric region, additional tests were conducted for possible effects of higher doses (up to 200 $\mathrm{mU} / \mathrm{L})$ over a longer time $(150 \mathrm{~min})$ in these preparations.

To further characterize the underlying mechanism of the insulin effect on the muscles of the abomasal corpus, the effect of insulin $(80 \mathrm{mU} / \mathrm{L})$ was tested in the presence of barium $(3 \mathrm{mmol} / \mathrm{L})$ as a blocker of $\mathrm{K}^{+}$channels, glybenclamide $(0.05 \mathrm{mmol} / \mathrm{L})$ as a blocker of ATPsensitive $\mathrm{K}^{+}$channels, and ouabain $(0.001 \mathrm{mmol} / \mathrm{L})$ as a blocker of the Na/K-ATPase. Pharmaceuticals were obtained from Sigma-Aldrich; chemicals were obtained from Merck KgAA (Darmstadt, Germany).

\section{Statistical Analysis}

Data were evaluated with the aid of SAS (version 9.1, SAS Institute, Cary, NC). Normal distribution was tested according to Kolmogorov-Smirnov. Because most data were not normally distributed, medians are given with their 25 th and 75 th percentiles or with minima and maxima as indicated. At first, the effect of a given substance was tested with ANOVA. Subsequently, values were compared between the different concentrations and between experimental and control tissues with Wilcoxon signed rank test for connected samples. $P$ values $<0.05$ were considered significant. The number of animals is given as N. Despite the same preparation techniques, all muscles strips differed slightly from one another in their initial contraction activity and contraction pattern. The changes in activity because of the addition of the various substances were quite similar for the muscle strips within a group. Therefore, significances became apparent despite a huge span from minimal to maximal values.

\section{RESULTS}

\section{Basal Contraction Activity}

Muscle strips from the abomasal corpus incubated in standard buffer solution had contraction amplitudes between 2.0 (minimum) and $55.1 \mathrm{mN}$ (maximum) with a median of $19.4 \mathrm{mN}$. The frequencies were rather con- stant and ranged from 1 to $5 /$ min with a median of $3 /$ min. This resulted in contraction activities between 6.9 and $246.2 \mathrm{mN} / \mathrm{min}$ with a median of $24.7 \mathrm{mN} / \mathrm{min}$. Muscle strips from the pyloric region had contraction amplitudes between 1.7 and $7.6 \mathrm{mN}$ with a median of $3.7 \mathrm{mN}$; the contraction frequencies ranged from 2 to $4 / \mathrm{min}$, with a median of $3 / \mathrm{min}$. This resulted in contraction activities between 4.2 and $17.2 \mathrm{mN} / \mathrm{min}$ with a median of $10.7 \mathrm{mN} / \mathrm{min}$. Almost all muscle strips showed a propensity to change their activity with time when incubated in the same buffer solution. During an incubation time of $2.5 \mathrm{~h}$, the contraction activity of muscles from abomasal corpus changed from 24.7 to $39.1 \mathrm{mN} / \mathrm{min}$ after $1 \mathrm{~h}$ and then to $23.5 \mathrm{mN} / \mathrm{min}$ after $2.5 \mathrm{~h}$. This was attributed to alterations in amplitude at constant frequencies. Muscle strips from the pyloric region doubled their contraction activity from 10.7 to $20.6 \mathrm{mN} / \mathrm{min}$ within $2.5 \mathrm{~h}$. Because of the time-dependent changes during the incubation period, adjacent samples were incubated from the same abomasal tissues in a second incubation chamber at the same time and were used as a time control.

\section{Effect of $\mathrm{K}^{+}$Concentration}

Reducing the $\mathrm{K}^{+}$concentration in the buffer solution to $1 \mathrm{mmol} / \mathrm{L}$ reduced the contraction amplitude in muscles from both corpus and pylorus to median values of $2.6 \mathrm{mN}$ ( 0 to $25.4 \mathrm{mN}$, corpus) and $1.5 \mathrm{mN}$ (0 to 5.7 $\mathrm{mN}$, pylorus); the frequencies of contraction were not affected. This resulted in contraction activities of 9.4 $\mathrm{mN} / \mathrm{min}$ in corpus (0 to $78.4 \mathrm{mN} / \mathrm{min}$ ) and of $3.5 \mathrm{mN} /$ $\mathrm{min}$ in the pyloric region (0 to $21.6 \mathrm{mN} / \mathrm{min}$ ).

An increase in $\mathrm{K}^{+}$concentration from 1 to $10 \mathrm{mmol} / \mathrm{L}$ increased the contraction amplitudes to median values of $6.3 \mathrm{mN}$ in corpus ( 0 to $64.8 \mathrm{mN}$ ) and to $7.5 \mathrm{mN}$ in pylorus (1.1 to $38.2 \mathrm{mN}$ ), with no effect on the frequencies of contraction. This increase in $\mathrm{K}^{+}$concentration increased the contraction activities to $29.9 \mathrm{mN} / \mathrm{min}$ in corpus (0 to $157.7 \mathrm{mN} / \mathrm{min}$ ) and to $33.6 \mathrm{mN} / \mathrm{min}$ in the pyloric region (3.8 to $152.6 \mathrm{mN} / \mathrm{min}$ ). The increase in contraction activity was significant $(P<0.05)$ within the range of $\mathrm{K}^{+}$concentrations that are of clinical interest $(1$ to $6 \mathrm{mmol} / \mathrm{L})$ and it was different $(P<0.05)$ from the time-dependent controls that received equal amounts of $\mathrm{NaCl}$ at the same time points (Figures 1 and 2).

\section{Effect of Insulin on Contraction Activity}

Muscles from the pyloric region showed no reactions to insulin that were significantly different from the time-dependent controls, neither when increasing doses were applied (Figure 3) nor when high doses of insulin 


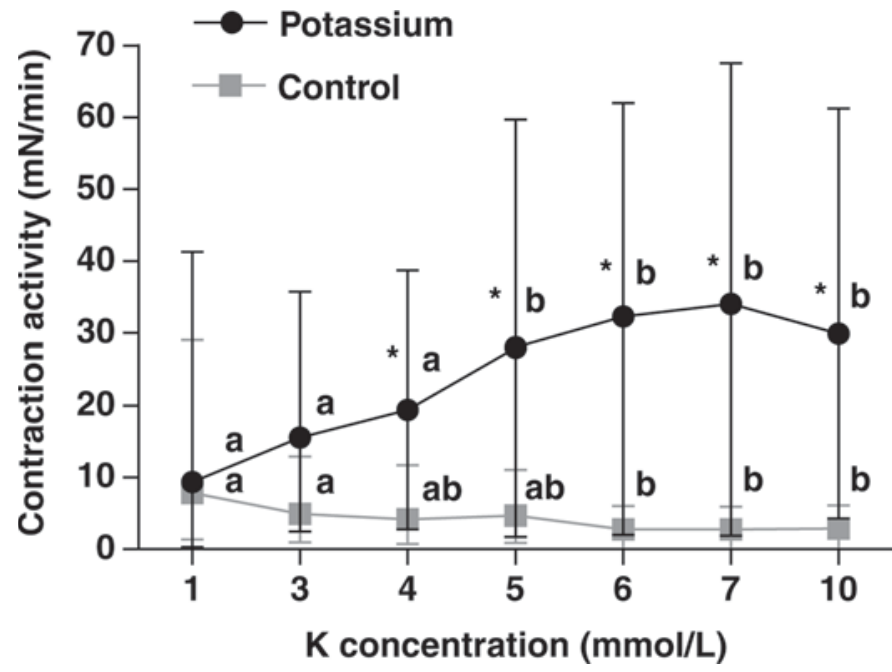

Figure 1. Effect of potassium on the contraction activity of circular muscles from the abomasal corpus. Control tissues were supplemented at the same time with equimolar amounts of $\mathrm{NaCl}$. Median values are given with their interquartile range $(\mathrm{n}=10)$. The ANOVA for connected samples showed an effect of $\mathrm{K}^{+}$on contraction activity. Signed rank test: significant differences between the concentrations are indicated with different letters; significant differences $(P<0.05)$ between control and $\mathrm{K}^{+}$-treated tissues are marked with an asterisk.

(up to $200 \mathrm{mU} / \mathrm{L}$ ) were applied for a longer period of time (up to 150 min; data not shown).

In contrast, insulin reduced amplitudes as well as the activity of contractions in the corpus muscles (Figure 4). Increasing the insulin concentration from 0 to 120

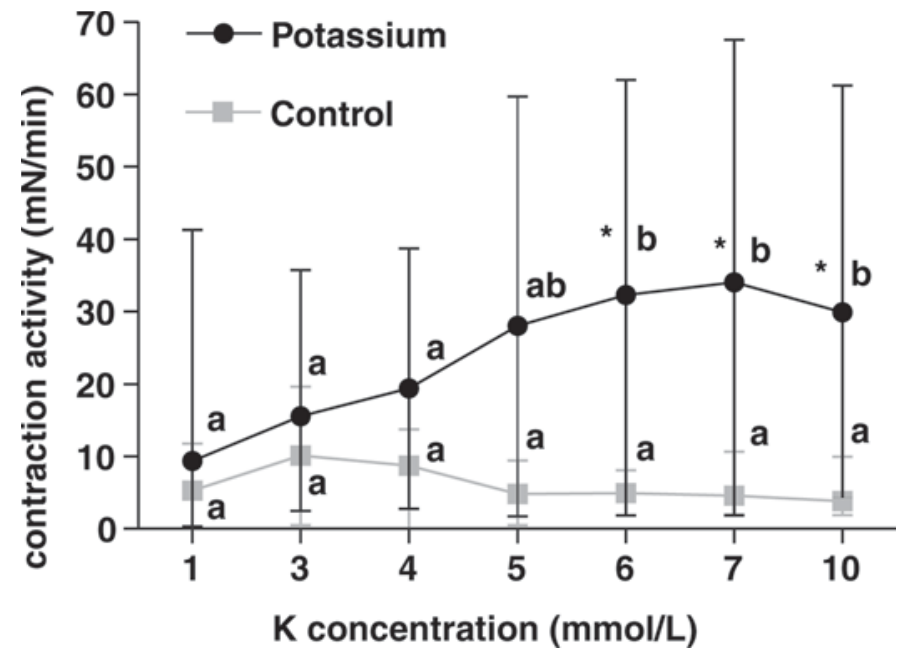

Figure 2. Effect of potassium on the contraction activity of circular muscles from the pylorus. Control tissues were supplemented at the same time with equimolar amounts of $\mathrm{NaCl}$. Median values are given with their interquartile range $(n=10)$. The ANOVA for connected samples showed an effect of $\mathrm{K}^{+}$on contraction activity. Signed rank test: significant differences $(P<0.05)$ between the concentrations are indicated with different letters; significant differences between control and $\mathrm{K}^{+}$-treated tissues are marked with an asterisk.
$\mathrm{mU} / \mathrm{L}$ reduced the amplitudes from $22.2 \mathrm{mN}$ (2.0 minimum, 115.1 maximum) to $6.13 \mathrm{mN}$ (1.8 minimum, 65.7 maximum) and the contraction activities from 34.53 $\mathrm{mN} / \mathrm{min}$ (3.48 minimum, 186.39 maximum) to 12.01 $\mathrm{mN} / \mathrm{min}$ (4.41 minimum, 78.97 maximum), whereas the frequencies remained constant.

\section{Insulin Effects in the Presence of $K$ Transport Blockers}

To characterize the underlying mechanisms of the insulin effect on muscles from the abomasal corpus, blockers of $\mathrm{K}^{+}$channels (barium, glybenclamide) and of the Na/K-ATPase (ouabain) were used (Figures 5, 6 , and 7 ). The inhibiting effect of insulin on muscle contraction could be antagonized by the subsequent addition of barium, glybenclamide, or ouabain. Moreover, when the muscles were incubated in the presence of barium, glybenclamide, or ouabain, insulin showed no effect on contraction activity.

\section{DISCUSSION}

\section{Contraction Activity of Muscles from the Abomasum of Cows}

The current experiments show that samples of smooth muscles isolated from the circular muscles of the corpus and the pyloric region of the abomasum of cows retain a rhythmic contractile activity when incubated in vitro

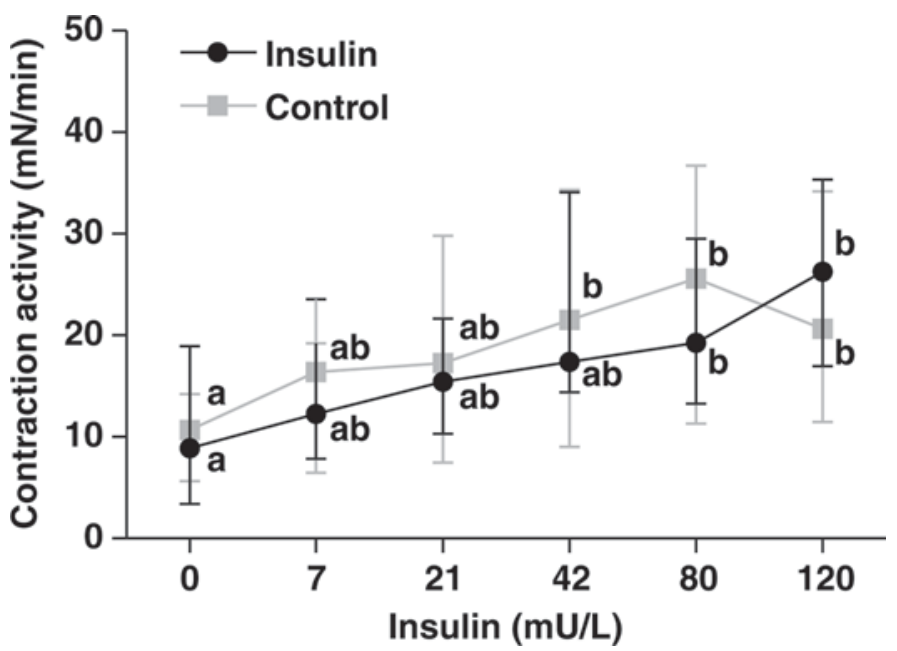

Figure 3. Effect of insulin on the contraction activity of circular muscles from the pylorus. Control tissues were supplemented at the same time with equal amounts of solvent. Median values are given together with their interquartile range $(\mathrm{n}=10)$. The ANOVA for connected samples showed an effect on contraction activity. Signed rank test: significant differences $(P<0.05)$ between the concentrations or time points are indicated with different letters; differences between control and insulin-treated tissues were not apparent. 


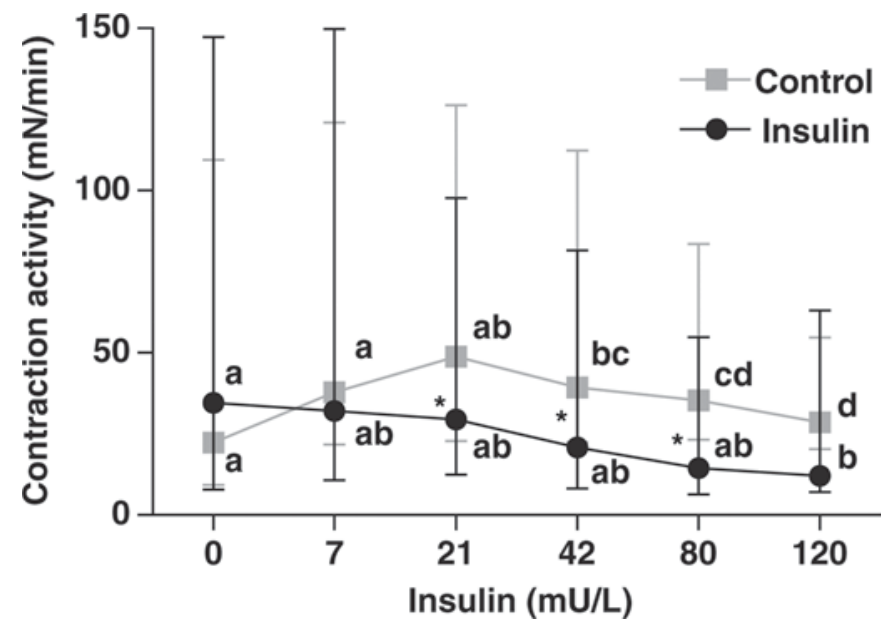

Figure 4. Effect of insulin on the contraction activity of circular muscles from the abomasal corpus. Control tissues were supplemented at the same time with equimolar amounts of solvent. Median values are given with their interquartile range $(n=10)$. The ANOVA for connected samples showed an effect of insulin on contraction activity. Signed rank test: significant differences $(P<0.05)$ between the concentrations (insulin) or the adjacent time points (control) are indicated with different letters; significant differences between control and insulin-treated tissues are marked with an asterisk.

under isometric conditions. The contraction activities, amplitudes, and frequencies that were measured and calculated were in the same order of magnitude as those reported in previous experiments with circular muscles from the abomasal corpus of cows (Zulauf et al., 2002).

\section{Effect of Potassium on Contraction Activity}

An increase in $\mathrm{K}^{+}$concentrations within the bathing solution, thereby mimicking changes in the extracellular milieu, led to gradual increases in contraction activity of the incubated muscles (Figures 1 and 2). This stimulating effect of extracellular $\mathrm{K}^{+}$supported Morgan and Szurszewski (1980), who showed an effect of extracellular $\mathrm{K}^{+}$on the membrane potential of smooth muscles isolated from the canine stomach. Increasing the $\mathrm{K}^{+}$ concentration depolarized the membrane potential of smooth muscles in their experiments and increased the tension that was developed. In contrast, a decrease in extracellular $\mathrm{K}^{+}$concentration hyperpolarized the membrane potential of smooth muscle cells (Kuriyama, 1963) and reduced the time period during which the membrane potential reached the threshold potential for the opening of potential-sensitive $\mathrm{Ca}^{2+}$ channels (Noack et al., 1992). A low extracellular $\mathrm{K}^{+}$concentration reduces the contraction activity of muscles and can cause muscle paralysis and recumbency (Sattler et al., 1998; Peek et al., 2000).
An increase in extracellular $\mathrm{K}^{+}$concentration to higher values (from 9 to $27 \mathrm{mmol} / \mathrm{L}$ ) likewise affected membrane potentials in rabbit intestine (Kato et al., 2007) but additionally modulated inhibitory neurons, which led to a further change in smooth muscle activity. Whether the reaction of the abomasal muscles to $\mathrm{K}^{+}$ can be ascribed to a myogenic, a neurogenic, or a mixed origin cannot be deduced from the current studies. Our studies show that extracellular $\mathrm{K}^{+}$has a measurable influence on muscle contractility of abomasal tissues within the range of pathophysiologically relevant $\mathrm{K}^{+}$ concentrations (1 to $7 \mathrm{mmol} / \mathrm{L}$; Whitlock et al., 1975; Coffer et al., 2006, Divers and Peek, 2008).

\section{Hypokalemias In Vivo}

Hypokalemia has been observed repeatedly in dairy cows around parturition (Sattler et al., 1998; Peek et al., 2000). A reduction in DMI might be a cause of a decline in plasma $\mathrm{K}^{+}$(Clabough and Swanson, 1989). Further explanations would be an impaired gastrointestinal absorption, a shift of $\mathrm{K}^{+}$to the intracellular space because of disturbances in acid-base homeostasis or in hormone balances (like insulin), or a disproportionately high renal excretion (e.g., because of administration of

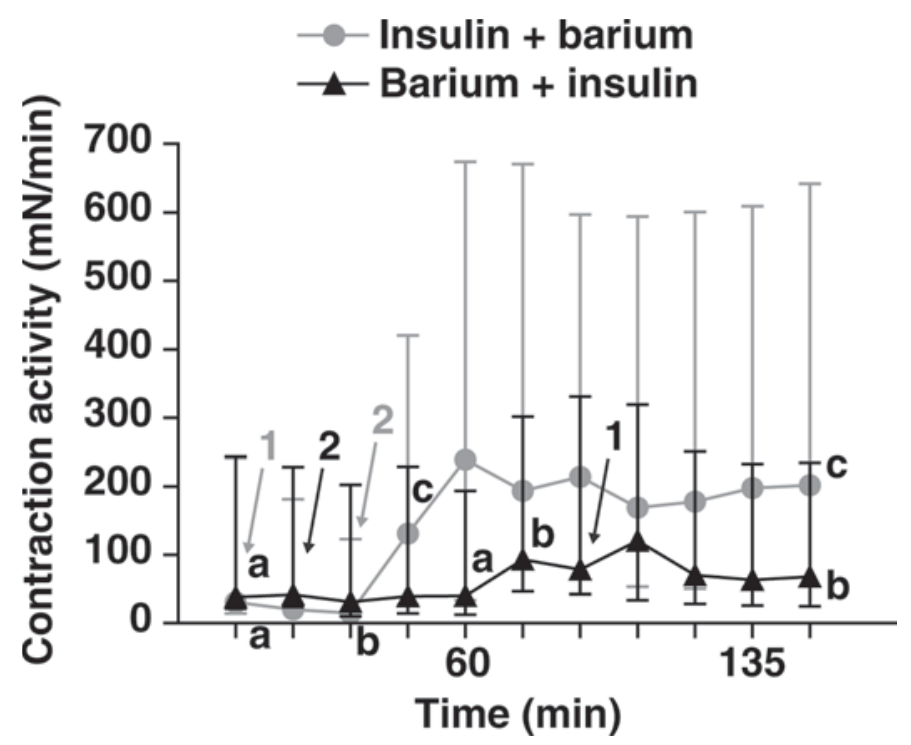

Figure 5. Influence of barium on the effect of insulin on the contraction activity of circular muscles from the abomasal corpus. Median values are given with their interquartile range $(n=10)$. The ANOVA for connected samples showed an effect of barium on contraction activity. Insulin + barium: the addition of $80 \mathrm{mU} / \mathrm{L}$ of insulin $(1$, at time $=2 \mathrm{~min})$ induced a decrease $(P<0.05)$ in contraction activity, and the subsequent addition of $3 \mathrm{mmol} / \mathrm{L}$ of $\operatorname{barium}(2$, at time $=32 \mathrm{~min}$ ) induced an increase $(P<0.05)$ in contraction activity. Barium + insulin: the addition of barium $(2$, at time $=17 \mathrm{~min})$ increased contraction $(P<0.05)$ activity, and the subsequent addition of insulin $(1$, at time $=92 \mathrm{~min}$ ) showed no further effect. Significant differences between adjacent points within 1 curve are indicated with different letters. 


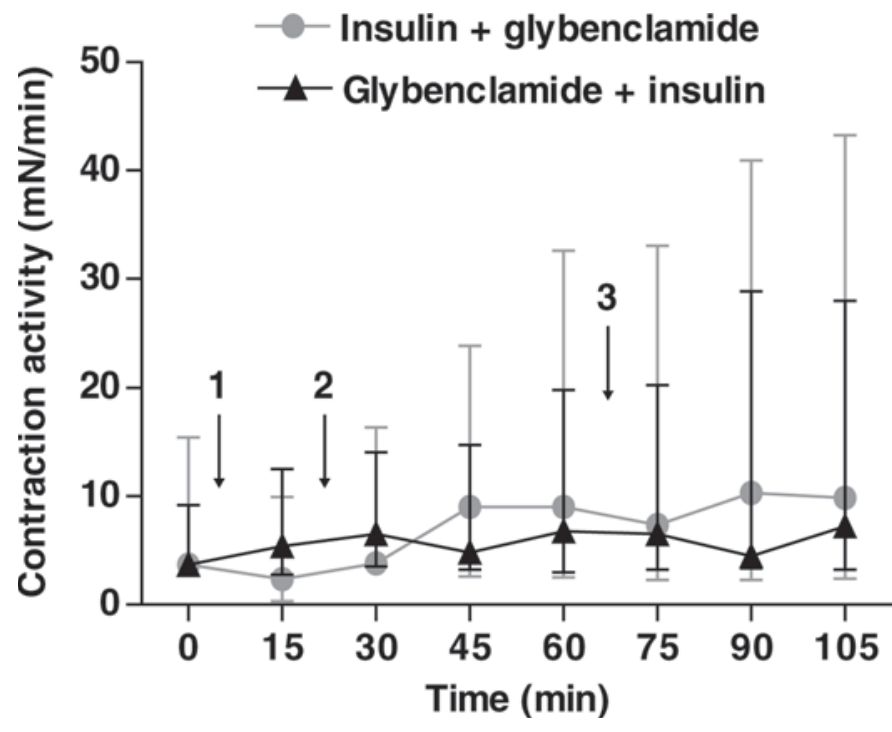

Figure 6. Influence of glybenclamide on the effect of insulin on the contraction activity of circular muscles from the abomasal corpus. Median values are given with their interquartile range $(\mathrm{n}=10)$. The ANOVA for connected samples showed an effect of glybenclamide on contraction activity. Insulin + glybenclamide: the addition of 80 $\mathrm{mU} / \mathrm{L}$ of insulin $(1$, at time $=2 \mathrm{~min})$ induced a decrease $(P<0.05)$ in contraction activity, and the subsequent addition of $0.05 \mathrm{mmol} / \mathrm{L}$ of glybenclamide $(2$, at time $=17 \mathrm{~min})$ induced an increase $(P<$ $0.05)$ in contraction activity. Glybenclamide + insulin: the addition of glybenclamide $(1$, at time $=2 \mathrm{~min})$ increased contraction $(P<0.05)$ activity, and the subsequent addition of insulin $(3$, at time $=62 \mathrm{~min})$ showed no further effect.

substances with mineralocorticoid activity; Sielman et al.,1997; Coffer et al., 2006).

\section{Effect of Insulin on Abomasal Activity}

Previous studies have shown that high doses of insulin (200 or $900 \mathrm{mU} / \mathrm{L})$ inhibited the abomasal efflux in vivo (Van Meirhaeghe et al., 1988a; Holtenius et al., 2000). Cows that underwent DA surgery and exhibited a prolonged reduction in myoelectric activity of the abomasal body and the pars pylorica had plasma insulin of 11 to $17 \mathrm{mU} / \mathrm{L}$ (sometimes up to $42 \mathrm{mU} / \mathrm{L}$ ), which were above reference levels (4 to $11 \mathrm{mU} / \mathrm{L}$ ), whereas cows with increased myoelectric activity after surgery had mean plasma insulin concentrations of 8 to $9 \mathrm{mU} / \mathrm{L}$ (Pravettoni et al., 2004, 2007). The results of our study show that insulin within pathophysiological levels (20 to $80 \mathrm{mU} / \mathrm{L}$ ) had a direct inhibitory effect on the circular muscles of the abomasal corpus (Figure 4). Because the activity of these muscles is essential for the propulsion of stomach contents toward the pylorus and duodenum, a reduction in their contraction activity could lead to a reduced abomasal efflux.

In in vivo studies, insulin reduced abomasal outflow in situations of hypo-, hyper- (Van Meirhaeghe et al., 1988a), and normoglycemia (Holtenius et al., 2000). We speculated that alterations not in glucose but in $\mathrm{K}^{+}$-dependent processes might be the underlying mechanism of the action of insulin. Our experiments show that the inhibiting effects of insulin on muscle contraction could be antagonized by the subsequent addition of $\mathrm{K}^{+}$ channel blockers (like barium and glybenclamide) or by the reduction in $\mathrm{Na} / \mathrm{K}$-ATPase activity because of subsequent addition of ouabain. Additionally, incubation of the muscles in the presence of these blockers abolished the effects of insulin on contractile activity. These observations would support an insulin effect on $\mathrm{K}^{+}$conductance as well as on the Na/K-ATPase in abomasal smooth muscle cells. Smooth muscle cells from abomasum would combine the insulin effects previously observed in vessels (Berweck et al., 1993; Standen and Quayle, 1998) and skeletal muscles (Clausen, 2003).

In contrast to the inhibiting effect of insulin on abomasal corpus, circular muscles from the bovine pylorus increased their activity in the presence of insulin, but this was not different from the time-dependent increase in control tissues. In tissues from goat pylorus a higher activity was observed in the presence of insulin that was significantly different from the activity of the control tissues (our unpublished data). An increased contraction of the pylorus in the presence of high doses of insulin could further reduce abomasal outflow and

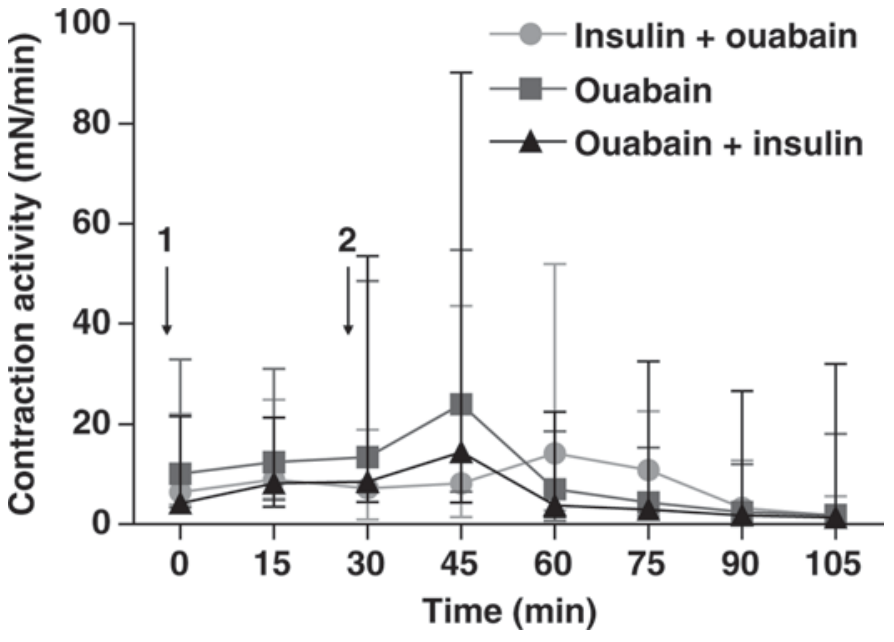

Figure 7. Influence of ouabain on the effect of insulin on the contraction activity of circular muscles from the abomasal corpus. Median values are given with their interquartile range $(\mathrm{n}=10)$. The ANOVA for connected samples showed an effect of ouabain on contraction activity. Ouabain induced a nominal increase in contraction activity that was followed by a significant decline $(P<0.05) 30$ to 45 min later. The insulin-dependent decrease in contraction activity did not reach significance in these muscle strips. In the presence of ouabain, insulin showed no effect. $1=$ first addition at time $=2 \mathrm{~min}, 80 \mathrm{mU} / \mathrm{L}$ of insulin or $0.001 \mathrm{mmol} / \mathrm{L}$ of ouabain; $2=$ second addition at time $=32 \mathrm{~min}$, $0.001 \mathrm{mmol} / \mathrm{L}$ of ouabain or $80 \mathrm{mU} / \mathrm{L}$ of insulin. The ouabain group received only 1 addition of ouabain at time $=2 \mathrm{~min}$. 
aggravate the disease, but there is no evidence for this additional pathogenetic factor from our experiments with pyloric tissues from cows. The discrepancies between abomasal corpus and pylorus, as well as between the pyloric regions of cows and goats, would agree with the observation that different parts of the gastrointestinal tract show different reactions to changes in insulin levels (Buéno and Ruckebusch, 1976).

\section{CONCLUSIONS}

The current study shows that a decrease in extracellular $\mathrm{K}^{+}$or an increase in extracellular insulin concentrations within pathophysiological limits are both able to affect the contraction activity of abomasal muscles. Low $\mathrm{K}^{+}$or high insulin concentrations reduced the activity of the circular muscle of the abomasal corpus (i.e., of the part that is responsible for the propulsion of abomasal chymus). The effect of insulin could be abolished by barium, glybenclamide, or ouabain; the underlying mechanisms of the insulin action could be an increased $\mathrm{K}^{+}$conductance or an increased $\mathrm{Na} / \mathrm{K}$ ATPase activity or both.

\section{ACKNOWLEDGMENTS}

This work was supported by the German Research Foundation (DFG) and the H. Wilhelm Schaumann Foundation.

\section{REFERENCES}

Berweck, S., H. Thieme, A. Lepple-Wienhues, H. Helbig, and M. Wiederholt. 1993. Insulin-induced hyperpolarization in retinal capillary pericytes. Invest. Ophthalmol. Vis. Sci. 34:3402-3407.

Buéno, L., and M. Ruckebusch. 1976. Insulin and jejunal electrical activity in dogs and sheep. Am. J. Physiol. 230:1538-1544.

Chen, J. Z., A. W. Deng, and J. F. Xu. 2005. Electroenterogram manifestations and significance in hypokalemia. Di Yi Jun Yi Da Xue Xue Bao 25:7-9.

Clabough, D. L., and C. R. Swanson. 1989. Heart rate spectral analysis of fasting-induced bradycardia of cattle. Am. J. Physiol. Regul. Integr. Comp. Physiol. 257:R1303-R1306.

Clausen, T. 2003. Na+-K+ pump regulation and skeletal muscle contractility. Physiol. Rev. 83:1269-1324.

Coffer, N. J., N. Frank, S. B. Elliott, C. D. Young, and S. R. van Amstel. 2006. Effects of dexamethasone and isoflupredone acetate on plasma potassium concentrations and other biochemical measurements in dairy cows in early lactation. Am. J. Vet. Res. $67: 1244-1251$.

Delgado-Lecaroz, R., L. D. Warnick, C. L. Guard, M. C. Smith, and D. A. Barry. 2000. Cross-sectional study of the association of abomasal displacement or volvulus with serum electrolyte and mineral concentrations in dairy cows. Can. Vet. J. 41:301-305.

Dirksen, G. 1961. Die Erweiterung, Verlagerung und Drehung des Labmagens beim Rind. Zentralbl. Veterinarmed. [C] 8:934-1015.

Divers, T. J., and S. F. Peek. 2008. Rebhun's Diseases of Dairy Cattle. Elsevier Health Sciences, Oxford, UK.

Doll, K., M. Sickinger, and T. Seeger. 2009. New aspects in the pathogenesis of abomasal displacement. Vet. J. 181:90-96.
El-Attar, H. M., Y. M. Abd El-Raof, and M. M. Ghanem. 2007. Alterations in the clinical, hematological and biochemical pictures in abomasal displacement in cows in Egypt. B.S. Vet. Med. J. 5th Scientific Conference:102-109.

Geishauser, T. 1995. Abomasal displacement in the bovine-A review on character, occurrence, aetiology and pathogenesis. J. Vet. Med. A $42: 229-251$.

Giesecke, D. 1986. Insulin deficiency and metabolic disorders in highyielding dairy cows. J. S. Afr. Vet. Assoc. 57:67-70.

Holtenius, K., S. Agenäs, C. Delavaud, and Y. Chilliard. 2003. Effects of feeding intensity during the dry period. 2. Metabolic and hormonal responses. J. Dairy Sci. 86:883-891.

Holtenius, K., K. Sternbauer, and P. Holtenius. 2000. The effect of the plasma glucose level on the abomasal function in dairy cows. J. Anim. Sci. 78:1930-1935.

Kato, K., Y. Kito, and H. Suzuki. 2007. Mechanical and electrical responses modulated by excitation of inhibitory nerves during stimulation with high-potassium solutions in circular smooth muscle of the rabbit rectum. J. Smooth Muscle Res. 43:229-246.

King, J. N., and E. L. Gerring. 1988. Actions of a novel gastrointestinal pro kinetic agent cisapride on equine bowel motility. J. Vet. Pharmacol. Ther. 11:314-321.

Kuiper, R., and H. J. Breukink. 1988. Myo-electric activity patterns on the abomasal body in the adult cow recorded with stainless steel electrodes. J. Vet. Med. A 35:340-346.

Kuriyama, H. 1963. The influence of potassium, sodium and chloride on the membrane potential of the smooth muscle of taenia coli. J. Physiol. 166:15-28.

Morgan, K. G., and J. H. Szurszewski. 1980. Mechanisms of phasic and tonic actions of pentagastrin on canine gastric smooth muscle. J. Physiol. 301:229-242.

Noack, T., P. Deitmer, and E. Lammel. 1992. Characterization of membrane currents in single smooth muscle cells from the guineapig gastric antrum. J. Physiol. 451:387-417.

Peek, S. F., T. J. Divers, C. Guard, A. Rath, and W. C. Rebhun. 2000. Hypokalemia, muscle weakness, and recumbency in dairy cattle. Vet. Ther. 1:235-244.

Pravettoni, D., K. Doll, M. Hummel, E. Cavallone, N. Morandi, and A. G. Belloli. 2007. Glucose tolerance test during abomaso-duodenal electromyography in three cows operated for left displaced abomasum. Dtsch. Tierarztl. Wochenschr. 114:58-63.

Pravettoni, D., K. Doll, M. Hummel, E. Cavallone, M. Re, and A. G. Belloli. 2004. Insulin resistance and abomasal motility disorders in cows detected by use of abomasoduodenal electromyography after surgical correction of left displaced abomasum. Am. J. Vet. Res. 65:1319-1324.

Rohn, M., B.-A. Tenhagen, and W. Hofmann. 2004. Survival of dairy cows after surgery to correct abomasal displacement: 2 . Association of clinical and laboratory parameters with survival in cows with left abomasal displacement. J. Vet. Med. A 51:300-305.

Sattler, N., G. Fecteau, C. Girard, and Y. Couture. 1998. Description of 14 cases of bovine hypokalaemia syndrome. Vet. Rec. 143:503507.

Sen, I., M. Ok, and A. Coskun. 2006. The level of serum ionised calcium, aspartate aminotransferase, insulin, glucose, betahydroxybutyrate concentrations and blood gas parameters in cows with left displacement of abomasum. Pol. J. Vet. Sci. 9:227-232.

Shaver, R. D. 1997. Nutritional risk factors in the etiology of left displaced abomasum in dairy cows: A review. J. Dairy Sci. 80:2449-2453.

Sielman, E. S., R. W. Sweeney, R. H. Whitlock, and R. Y. Reams. 1997. Hypokalemia syndrome in dairy cows: 10 cases (1992-1996). J. Am. Vet. Med. Assoc. 210:240-243.

Standen, N. B., and J. M. Quayle. 1998. K+ channel modulation in arterial smooth muscle. Acta Physiol. Scand. 164:549-557.

Trenkle, A. 1970. Effects of short-chain fatty acids, feeding, fasting and type of diet on plasma insulin levels in sheep. J. Nutr. 100:1323-1330.

Van Meirhaeghe, H., P. Deprez, C. Van den Hende, and E. Muylle. 1988a. The influence of insulin on abomasal emptying in cattle. J. Vet. Med. A 35:213-220. 
Van Meirhaeghe, H., P. Deprez, C. Van den Hende, and E. Muylle. 1988b. Plasma glucose clearance and insulin response in cows with abomasal displacement. J. Vet. Med. A 35:221-228.

Van Winden, S. C. L., R. Jorritsma, K. E. Müller, and J. P. T. M. Noordhuizen. 2003. Feed intake, milk yield and metabolic parameters prior to left displaced abomasum in dairy cows. J. Dairy Sci. 86:1465-1471.

Whitlock, R. H., J. B. Tasker, and B. C. Tennant. 1975. Hypochloremic metabolic alkalosis and hypokalemia in cattle with upper gastrointestinal obstruction. Am. J. Dig. Dis. 20:595-596.

Yasui, S., K. Mawatari, T. Kawano, R. Morizumi, A. Hamamoto, H. Furukawa, K. Koyama, A. Nakamura, A. Hattori, M. Nakano,
N. Harada, T. Hosaka, A. Takahashi, S. Oshita, and Y. Nakaya. 2008. Insulin activates ATP-sensitive potassium channels via phosphatidylinositol 3-kinase in cultured vascular smooth muscle cells. J. Vasc. Res. 45:233-243.

Zadnik, T. 2003. A comparative study of the hemato-biochemical parameters between clinically healthy cows and cows with displacement of the abomasum. Acta Vet. (Beogr.) 53:297-309.

Zulauf, M., C. Spring, R. Eicher, M. Meylan, G. Hirsbrunner, G. Scholtysik, and A. Steiner. 2002. Spontaneous in vitro contractile activity of specimens from the abomasal wall of healthy cows and comparison among dairy breeds. Am. J. Vet. Res. 63:1687-1694. 